\title{
Retraction: Mutations in CLCN2 encoding a voltage-gated chloride channel are associated with idiopathic generalized epilepsies
}

Karsten Haug, Maike Warnstedt, Alexi K Alekov, Thomas Sander, Alfredo Ramírez, Barbara Poser, Snezana Maljevic, Simon Hebeisen, Christian Kubisch, Johannes Rebstock, Steve Horvath, Kerstin Hallmann, Joern S Dullinger, Birgit Rau, Fritz Haverkamp, Stefan Beyenburg, Herbert Schulz, Dieter Janz, Bernd Giese, Gerhard Müller-Newen, Peter Propping, Christian E Elger, Christoph Fahlke, Holger Lerche \& Armin Heils

Nat. Genet. 33, 527-532 (2003); published online 3 March 2003

Re-examination of the families and the molecular genetic data by a neurologist and a geneticist who were not involved in the original study has revealed major differences from the published data in two of the three published pedigrees (presented in Figs. 1a,b of the original publication). The number of clinically affected individuals was much lower than was previously reported, and large parts of the pedigree structures and epilepsy phenotypes are different. Most importantly, re-examination revealed the existence of several asymptomatic mutation carriers, refuting the complete co-segregation of the two mutations with the clinical phenotypes that was originally reported. A detailed description of these differences, including the clinical phenotypes and the genetic reanalysis, is provided in the related Correspondence in this issue ${ }^{1}$.

We sincerely regret our failure to recognize that important family data were false before the original manuscript was published, and we apologize for any inconvenience that may have arisen as a result of our report.
A. Heils did not agree to coauthor this retraction.

1. Kleefuß-Lie, A. et al. Nat. Genet. 41, 954-955 (2009). 